\title{
Values Realized in Personal Strivings and Motivation, and Meaning in Life in Polish University Students
}

\author{
Zuzanna Siwek $^{1} \cdot$ Anna Oleszkowicz ${ }^{1} \cdot$ Aleksandra Słowińska $^{1}$
}

Published online: 12 April 2016

(C) The Author(s) 2016. This article is published with open access at Springerlink.com

\begin{abstract}
The present study was based on two theoretical conceptions-Deci and Ryan's self-determination theory and its characteristic approach to values, and the conception of meaning in life derived from the Logotherapy of Frankl. The aim of the study was to verify the thesis that values realized in personal strivings play a significant role in experiencing meaning in life. The study was also designed to explore the relationships between types of motivation and meaning in life. A semi-open method was used to study values and striving motivations, one based on the Personal Striving Assessment by Emmons and the Purpose in Life Test by Maholick and Crumbaugh. The sample comprised 353 students of Wrocławbased universities (159 women and 194 men). The findings of this study demonstrated that meaning in life is related to motivation as well as to certain values that participants reported as realized in their personal strivings. Predictors of meaning in life were the value of financial success for men, and the value of intimacy/friendship for women. Another predictor of meaning for both groups was external motivation. Further interesting results discussed in this paper were obtained by comparing individuals with low and those with high levels of meaning in life. The latter group was found to attribute greater importance to autonomous motivation and to attach greater meaning to their everyday strivings by associating them more closely with both intrinsic and extrinsic values.
\end{abstract}

Keywords Values $\cdot$ Self-determination $\cdot$ Motivation $\cdot$ Strivings $\cdot$ Meaning in life

\section{Introduction}

The need for meaning in life, which attains its existential significance in adolescence and the stages of human development that follow it, is strongly related to developing selfidentity, searching for one's place in the world, and taking up specific social roles.

Zuzanna Siwek

z.siwek@psychologia.uni.wroc.pl

1 Institute of Psychology, Wroclaw University, Dawida Street 1, 50-527 Wroclaw, Poland 
Achieving meaning in life is doubtless related to performing goal-oriented activities (e.g. Ryff and Singer 1998a, b; Emmons 2003a, b). Cognitively oriented researchers (e.g. Bandura 1996) point out that developing meaning in life is influenced more by the process of setting, achieving, and possibly also evaluating one's goals than by the fact of these goals' being tied to any specific values.

In contrast, others claim the need for meaning in life is best satisfied by distinguishing an actual intention for action, that is, its overriding reason associated with specific values. This relationship is emphasized by existential and humanistic psychologists, as well as those applying self-determination theory (SDT; Frankl 1959/2006; Maslow 1962; Emmons 2003a; Straś-Romanowska 2005; Weinstein et al. 2012).

\subsection{Meaning in Life and Values}

According to Frankl, the precursor of exploring and studying meaning in life, the essence of human existence manifests itself in taking on responsibility and living one's life in freedom and consistently with one's values. Correspondingly, he believed the sense of feeling lost was the source of a wide range of problems, including addictions, depression, aggression, and neurosis. Thus, the sense of disorientation and lack of meaning in life results from peoples' downplaying the importance of spiritual life and their preference for "having" over "being" (Frankl 1978, 1959/2006).

In line with the assumptions of Logotherapy, an individual who has attained meaning in life is capable of living a richly satisfying, purposeful, and fulfilling life, an aspect pointed out by several other researchers as well (see Ryff and Singer 1998a, b; Emmons 2003b).

However, when writing about a fulfilling life, Frankl does not necessarily mean a pleasant one. As he points out, people find meaning in life also in difficult circumstances accompanied by distress and negative affect, and where many of their basic needs remain unfulfilled. This is because even in the time of hardship, struggle, and extreme danger one may retain meaning in life by clinging to universal values, such as love and relationships with the loved ones (Frankl 1959/2006), an observation also made by others who explore the subject of meaning in life (e.g. Reker 2000).

It is perhaps for the reason that meaning in life does not always go hand in hand with pleasure that researchers exhibiting a hedonistic orientation rarely perceive this variable as an indicator of a fulfilling life. Conversely, Frankl's perspective on meaning in life and values appears congruent with the view of well-being derived from eudaimonia, which puts emphasis on searching for one's own true self and attaining fulfillment by acting in accordance with one's authentic, if often limited, capabilities (Waterman 1993). Importantly, living by one's values and searching for happiness does not necessarily run contrary to experiencing pleasure and joy, a thesis empirically supported by the results of an interesting study by Huta (2012). The researcher found the children whose parents cherished values and strove for happiness derived from eudaimonia to also express such attitudes in their lives. Furthermore, those children derived their happiness from both eudaimonia and hedonia, which made them stand in clear contrast to the children whose parents role modeled only hedonia, making them capable of deriving well-being from that one source only. Therefore, meaning in life and its underlying values appear to form a strong foundation for human happiness in its broad, eudaimonic meaning. Numerous researchers rank meaning in life among the key aspects of well-being (e.g. Ryff and Singer 2006; Seligman 2011; King et al. 2006; de Muijnck 2013). Also within SDT, which served as the theoretical framework for this study, suggestions can be found that meaning in life be treated as an important indicator of eudaimonic well-being (Weinstein et al. 2012). In 
line with such a eudaimonic outlook on well-being, we regard meaning in life to be a vital element making up human happiness.

When writing about meaning in life and well-being it is also worth mentioning a recent study by Cohen and Cairns (2012), who advocate a distinction between the two terms of "having meaning in life" and "searching for meaning in life". The researchers suggest that the latter is accompanied by tension and distress that reduce an individual's well-being. Conversely, finding meaning in one's current life and developing it further (having meaning in life), increases one's sense of happiness and satisfaction. However, in the mentioned aspects, and their connections with well being, there are significant cultural differences (e.g. Steger et al. 2008; Kossakowska et al. 2013).

In this work, as in the presented study, meaning in life is perceived in the context of personal strivings. Emmons (1986) defines personal strivings as everyday endeavors: behavior aimed at attaining important long-term goals. Research on personal strivings has traditionally had an open formula, in which participants independently make a list of their strivings by determining and writing them down. The two constructs that are similar to personal strivings are personal projects (e.g. Little 1983) and life tasks (Cantor et al. 1991). Personal strivings can be more general, e.g. "I try to make other people happy", as well as more precise, e.g. "I try to read interesting books every day". They can also be analyzed in a variety of ways, one of which involves analyzing the motivations these strivings stem from, while another focuses on analyzing the values which the strivings help individuals to realize. Both of these ways were employed in our study.

In this paper, values are understood in line with the definition proposed by Kasser and Ryan (1993, 1996), who distinguish between intrinsic and extrinsic values. This distinction was made based on Fromm's reflections on the values revolving around the conflict of having versuss being, on a host of theories by Rogers and Maslow, and on SDT (Kasser and Ryan 1996). Intrinsic values include those conducive to fulfilling basic psychological needs (autonomy, relatedness, and competence), higher personality integration, and improving the well-being of the individual (Kasser and Ryan 1993, 1996; Sheldon and Kasser 2000; Kasser and Ahuvia 2002; Martos and Kopp 2012); these are: emotional intimacy and friendship, self-acceptance and personal growth, and community contribution. In turn, extrinsic values include: money and financial success, popularity/recognition, and physical appearance. The fulfillment of the extrinsic values is usually motivated by the desire for material rewards or building one's self-esteem based on the favorable opinions and admiration of others (Sheldon and Kasser 2000). Such a motivation is not conducive to fulfilling the innate psychological needs of human beings.

The division into intrinsic and extrinsic values is also characteristic of the perception of values under SDT. It is a reflection of an important thesis that a healthy and fulfilling functioning of a human being does not only consist in setting and effectively pursuing one's goals, but also takes account of the content and the underpinning values of these strivings. In other words, it is also crucial what constitutes the driving force behind people's strivings. This perspective is supported by a wealth of research on the relationships between broadly defined well-being (vitality, life satisfaction, depression, affect, selfactualization, and physical symptoms) and values (Sheldon and Kasser 1995, 1998, 2000; Sheldon et al. 2004). Valuing money, popularity, or physical appearance over other strivings has been found to be negatively correlated with health, vitality, and broadly conceived well-being, an effect observed across many countries and cultures (e.g. Schmuck and Kasser 2000; Martos and Kopp 2012; Ryan et al. 1999; Kokonyei et al. 2008). Apart from the results of correlation studies, also available are findings of several experiments that confirm the discussed relationship. For instance, a meta-analysis 
conducted by Kasser (2013) shows a negative relationship between materialistic values and well-being to be most pronounced in the citizens of wealthy countries, and relatively weaker in individuals living in less developed countries.

The results mentioned above cannot be interpreted as an explicit proof for a relationship between values and meaning in life. There are several points of similarity between our study and those of Sheldon and Kasser (1995), and Sheldon et al. (2004), which inspired our work, and include a focus on the relationships between motives, values and well-being, as well as making use of Emmons' procedure for assessing personal strivings. These similarities allowed us to compare the findings across all these the studies with respect to the motives-values relationships (the results of this comparison are given in the Preliminary Analyses section below).

In contrast, a significant difference between the present work and the studies mentioned above is that whereas others concentrated on a broadly defined well-being (without taking account of meaning in life as an aspect of well-being), we focused on values and motives with a view to finding among them the predictors of meaning in life.

Another important difference lies in the sample: here, we studied a cohort of Polish students, who differ from their American counterparts owing to cultural and socioeconomic factors.

By incorporating meaning in life, our work goes beyond the framework of SDT-based study of values, where only a percentage of work focuses on meaning in life, such as the study by Martos and Kopp (2012). However, also this work lends itself to no direct analogy, as the researchers explored values in aspirations, rather than in personal strivings.

In line with their authors' expectations, the studies mentioned above demonstrated intrinsic aspirations, ${ }^{1}$ as opposed to extrinsic ones, to be a better predictor of meaning in life. In turn, Weinstein et al. (2012) took a more detailed approach to meaning in life by employing a number of additional variables, such as will to meaning, seeking meaning, and experiencing meaning. Their results demonstrated individuals with strong intrinsic aspirations to desire, seek, and experience meaning in a considerably more intense way than those who prioritize extrinsic aspirations. This can be seen as yet another argument supporting the observation that the content of personal strivings and their connection with certain values may be a significant correlate of meaning in life, even though the authors of the above-mentioned study admit their endeavor is of an exploratory character and, such as, requires further verification.

A vast majority of the studies mentioned above present findings obtained for highly developed and wealthy countries, where the perception of values, in particular those related to material goods, may be different from the one prevailing in less affluent countries. Moreover, those studies focused mainly on life aspirations, while the present study takes personal strivings as its point of departure toward the reflection on the values these

\footnotetext{
1 Both intrinsic and extrinsic aspirations, and intrinsic and extrinsic values are very similar constructs. Intrinsic aspirations are certain life goals that reflect a number of values, such as relationships with others, personal development, and contribution to community life. Likewise, extrinsic aspirations reflect extrinsic values: popularity, money, and physical appearance. The difference between the aspirations and values, then, lies in how they are studied. Aspirations are tested by using the Aspiration Index (Kasser and Ryan 1996), in which participants respond to a set of 35 life goals (e.g. "To keep up with fashions in hair and clothing", "To have my name appear frequently in the media") by grading, on a 7-point scale, the importance of each goal, the likelihood that it will be attained, and the current level of attainment of each goal. In contrast, the study of values is performed by analyzing individuals' personal strivings: study participants are first asked to individually make a list of their strivings (i.e. some sort of goals) and then to analyze the extent to which these strivings help them fulfill a set of values proposed and described by the researcher (from a prepared list of values).
} 
strivings help individuals to realize. For these reasons, exploring the relationship between the values realized in everyday personal strivings and meaning in life in a sample of young Poles offers an interesting scientific challenge, one that can be addressed to help fill the gaps in the current state of knowledge in the field.

\subsection{Motivation as the Prerequisite for Meaning in Life}

Under SDT, environments that facilitate the fulfillment of the three basic psychological needs (autonomy, relatedness, and competence) are also conducive to developing and strengthening autonomus motivation in individuals who function in those environments (Ryan and Deci 2000). The behavior and strivings of intrinsically motivated individuals are directed by their interest, curiosity, and pleasure. Individuals whose behavior is a result of autonomous motivation-hence, it is mainly underpinned by intrinsic motivation and identification (when the action is accepted or regarded as personally important) - are more willing to explore and are characterized by greater vitality, creativity, as well as better health (Sheldon 1995; Sheldon et al. 1996; Reis et al. 2000; Deci et al. 2001; Patrick et al. 2007). In other words, such people display a more active attitude toward the world around them. The more individuals are subjected to autonomous motivation the more they act in accordance with their beliefs and values, also exhibiting higher levels of coherence (Weinstein et al. 2012). In sum, intrinsic motivation and identification are conducive to greater exploration, self-awareness, and integration of an individual, making these motives a likely foundation for creating one's meaning in life (Weinstein et al. 2012).

Several empirical premises suggest that Weinstein et al.'s theoretical assumptions concerning the relationships between motivation and meaning in life may find confirmation in research. One of these assumptions is the research conducted by Allport and Ross (1967), in which individuals with an intrinsic orientation toward religiosity (which corresponded to autonomous motivation) were found to be characterized by higher meaning in life. Another, the latest study by Bailey and Phillips (2015), where it was shown that intrinsic motivation is associated with the presence of meaning.

The research under SDT to date suggests that the basic psychological needs are conducive to the development of intrinsic motivation and a higher meaning in life (Weinstein et al. 2012). As of yet, there is little clarity as to how the relationship between these three variables works. Autonomous motivation could perhaps serve as a mediator between fulfilling the basic psychological needs and achieving meaning in life.

For reasons of limited space, we have chosen to explore here only a fragment of this relationship, one concerning different motives and meaning in life. Of course, the relationship in its entirety deserves a comprehensive analysis, a path that we intend to follow in future research. Except for the examples provided above, researchers only infrequently focus their attention on exploring motivation and meaning life, even though the relationship of these variables is an interesting direction of research with sound theoretical basis.

\subsection{The Present Study}

The main aim of the present study was to test the hypothesis that values realized in personal strivings could play a significant role in experiencing meaning in life. Although the body of research reviewed above does not supply a satisfactory answer to the question of what kind of relationships exist between the values that young people realize in their personal strivings and their meaning in life, it has nevertheless helped us to give shape to our hypothesis: 
$\mathbf{H}_{1}$ Realizing intrinsic values in personal strivings is positively related to meaning in life.

As we intended to conduct a correlative study, we asked additional research questions to determine the direction of this relationship: Which of the values realized in personal strivings are the best predictors of meaning in life?; and do individuals with high meaning in life differ from those with low meaning in their perception of intrinsic and extrinsic values associated with personal strivings?

The second aim of the study was to explore the relationship between the types of motivation and meaning in life. In line with the theoretical assumptions, we proposed the following hypotheses:

$\mathbf{H}_{\mathbf{2 a}}$ Intrinsic motivation in personal strivings is positively related to meaning in life.

$\mathbf{H}_{\mathbf{2 b}}$ External motivation is negatively related to meaning in life.

We also asked two additional questions: Which types of motivation in personal strivings are good predictors of meaning in life?; and, do individuals with high meaning in life differ from those with low meaning in their perception of the motivations underpinning selfdetermination? One final issue we found worth investigating was whether the studied relationships were different for the two sexes.

Looking for answers to these questions was preceded by an analysis of the relationships between autonomous motivation and controlled motivation, and values. To the end of obtaining a complete picture of the issue at hand, we hold such an analysis is significant, if only auxiliary, as it makes it possible to find out whether autonomous motivation is related more strongly to intrinsic or extrinsic values. According to some researchers, this may serve as an indicator of personality coherence (Sheldon and Kasser 1995).

There are several reasons why we believe that exploring the relationships between meaning in life and values, and meaning in life and motivations behind personal strivings is a worthwhile and valid endeavor, reasons which also distinguish the present study from the research reviewed above. First, we decided to give the study of personal strivings an open form, making our study different from the majority of the already-mentioned research projects, which focused mainly on well-being and life aspirations. As noted above, the research on aspirations has so far been conducted by using closed questions. In contrast, by using open questions we were able to obtain statements formulated in participants' own words, a quality which contributed to their greater authenticity, also rendering them ever more useful for the investigation of values. Second, existing studies that include the variable of meaning in life have so far been largely conducted on individuals inhabiting well-developed countries. Conversely, the present study was carried out on a cohort of young Polish adults, thus fulfilling the extant gap and allowing for further development in the area of meaning in life, values, and motivations. Third, our study offered an opportunity to simultaneously investigate the relationships between meaning in life and values as well as personal motivations.

\section{Materials and Methods}

\subsection{Participants and Procedure}

Approximately 390 students took part in the study, of which 353 participants, comprising 159 women (45\%) and 194 men (55\%), completed all the administered surveys correctly. The 
sample was selected by convenience, rather than randomly, although we strove to maintain a balance between male and female participants, also trying to recruit students enrolled on a variety of different courses in both human and technical sciences. The study was carried out in Wrocław, a city in south-western Poland with several hundred thousand inhabitants. Participants, aged between 18 and 25 (mean age was $21, \mathrm{SD}=1.75$ ), were students at the University of Wrocław enrolled on the courses of Polish Philology (7.6\%), Romance Philology (10.2 \%), History (6.5\%), Law and Administration (20\%), and Psychology and Pedagogy (5\%); and at Wrocław University of Technology enrolled on Electronics and Electrotechnics (6.5\%), Telecommunication and Computer Science (17\%), Control Engineering and Robotics (10\%), and Architecture (9\%). In our sample, $8.2 \%$ of participants did not indicate their course of study. Studying was participants' main activity.

Questionnaires were completed in groups of 5-25 people during participants' classes, with informed consent given both by each participant and the lecturers. The study, which was carried out by trained experimenters and took around 45 min to complete, was fully anonymous. Participants were not rewarded in any way for taking part in the study, for example by receiving extra points or grades, although they were offered a chance to receive the findings of this research by email several months after the study took place.

\subsection{Measures}

\subsubsection{Meaning in Life}

Meaning in life was measured by using The Purpose in Life Test (PIL) by Crumbaugh and Maholick (1964), Crumbaugh (1968). A questionnaire used for assessing the level of meaning in life by determining individuals' subjective psychological state, the PIL is currently in common use both in Poland and around the world (e.g. Cepuch et al. 2014; Nygern et al. 2005; Brunelli et al. 2012; Schulenberg et al. 2011; Wu et al. 2013).

The scale was adapted to the Polish conditions by Płużek (Popielski 1987). It consists of three parts, A, B, and C, with the latter two-which have a semi-open form of participants' statements expressed in writing - being of a qualitative character and intended primarily for individual therapeutic work. The original version of Part A consists of 20 bipolar statements rated on a 7-point Likert-type scale, where 1 corresponds to statements expressing low meaning in life (e.g. I usually feel really despondent), and 7-to opposite statements, characteristic of high meaning (e.g. I usually feel enthusiastic and full of life). By selecting the numbers from 1 to 3 participants showed that the statement reflecting low meaning in life characterized them to a significant, moderate, or slight extent. In turn, by selecting the numbers from 5 to 7 participants showed they agreed more with the statement describing high meaning in life. Selecting the number 4 was a neutral choice indicating participants' lack of preference for either statement.

Despite its long tradition of use, the PIL has received only one Polish article with an analysis of structure (Życińska and Januszek 2011), one that in spite of meeting statistical requirements also gives rise to difficulties related to its theoretical assumptions and interpretation. For this reason, participants of the present study completed the PIL's original 20-item Part A, thus producing data for subsequent confirmatory factor analysis that was carried out to test several models proposed by others (Shek 1988; McGregor and Little 1998; Waisberg and Starr 1999; Morgan and Farsides 2009; Życińska and Januszek 2011). The results showed the best fit for the 10-item model by Morgan and Farsides (2009), which was found to be the optimal one also by Schulenberg and Melton (2010). In 
this light, we decided to base further analyses solely on the 10 items distinguished by Morgan and Farsides and to dispense with analyzing the remaining items of the original PIL.

That being said, a point must be made of the PIL's debatable validity, which has attracted considerable criticism in the literature. Some researchers questioned whether the tool does indeed measure meaning in life, as it produces results that are strongly dependent on the measures of respondents' mood, depression, and psychological distress (Dyck 1987; Yalom 1980; Steger et al. 2006). These doubts will be addressed in the section with the interpretation of our findings below.

The ten items included in Morgan and Farsides' model form two factors (dimensions): exciting life and purposeful life. The exciting life factor comprises 7 items (items 2, 5, 7, $10,17,18$, and 19 in the original PIL), for example: I think that life: has always something exciting to offer-is totally dull; My everyday tasks are: a source of fulfilment and satisfaction-bothersome and a horrible ordeal. The purposeful life factor is composed of 3 items (original items 3, 8, and 20), for example: In pursuing my life goals: I've never been really successful-I have always managed to satisfy my needs. Completing the 10 items produced a score ranging between 10 and 70, with the higher the score, the higher level of one's meaning in life. The two-factor model demonstrated satisfactory structure consistency $(\mathrm{GFI}=.95$, AGFI $=.91, \mathrm{CFI}=.95, \mathrm{RMSEA}=.07)$ and Cronbach's alpha reliability ( $\alpha=.81$ for the subscale of exciting life, $\alpha=.73$ for the subscale of purposeful life, $\alpha=.87$ for the whole 10-item PIL).

\subsubsection{Personal Strivings}

Personal strivings were measured by using Emmons' Personal Strivings Assessment (PSA), a tool for qualitative and quantitative analysis of personal strivings. In this method, participants individually compose a list of several to about a dozen of personal strivings and analyze them. The most popular and commonly used versions of the questionnaire allow for analyzing the strivings in connection with participants' appraisal of their involvement in pursuing the goal, the difficulty in attaining it, its meaningfulness, the reasons for pursuing it, and other attributes (Emmons 2003a).

In our study we decided to implement a part of Emmons' (1986, 2003a) method in conjunction with the ideas proposed by Sheldon and Kasser (1995, 1998, 2000) with respect to Parts $\mathrm{B}$ and $\mathrm{C}$ of the questionnaire.

The original PSA was translated into Polish by three independent translators, producing three Polish versions that were then translated back into English by a bilingual translator. Those three English versions were then compared with the original tool. The most accurate translations were chosen for each individual item and then compiled to form the final Polish version of the PSA. The Polish instrument consisted of three parts, A, B, and C. In completing Part A, participants were given a few minutes to reflect on and write down eight strivings, that is, things which they tried to do in their everyday lives. Because a percentage $(19.55 \%)$ of participants failed to produce 8 strivings, all the questionnaires with at least 5 strivings were eventually accepted for analysis. In Part B, participants analyzed each of their strivings with regard to their underlying motivations. The questionnaire contained a brief and easy-to-understand description of the four basic types of motivation derived from the taxonomy of behavior regulation by Deci and Ryan (1985) external motivation, introjected motivation, identified motivation, and intrinsic motivation. To illustrate, external motivation was called Motive 1 "Reward/Punishment" and described in the following way: You strive for this goal because somebody else wants you 
to, or because you'll get something from somebody if you do. Stated differently, you probably wouldn't strive for this if you didn't get some kind of reward, praise, or approval for it. For example, "Going to church regularly" might be a striving of yours because your parents would criticize you if you didn't (Emmons 2003a). Participants were to asses, on a 7-point scale, the extent to which they followed motives 1, 2, 3, and 4 in fulfilling each of their strivings.

In the final part of the questionnaire, Part $\mathrm{C}$, participants analyzed their strivings in relation to six so-called "possible futures", which correspond to intrinsic and extrinsic values distinguished by Kasser and Ryan (1996). The intrinsic values included in the questionnaire were: personal growth, community contribution, and intimacy/friendship; and the extrinsic values were: attractive appearance, popularity/recognition, and financial success. On a scale from 1 to 7, participants rated the extent to which fulfilling each of their strivings was conducive to attaining each of the six values: 1 expressed that fulfilling a given striving was not at all helpful in attaining a particular value, whereas 7 indicated that, when fulfilled, a given striving was especially helpful in attaining a particular value.

The PSA makes it possible to calculate the indicators for the four types of motivation. A motivation indicator is a sum of points assigned to a given type of motivation (e.g., introjection) in all the strivings, which is then divided by the number of strivings (results ranging from 1 to 7). Additionally, the four motives can be divided into autonomous and controlled ones. The indicator of autonomous motivation is the sum of points assigned to intrinsic motivation and identification in all the strivings, which is then divided by the number of strivings (results ranging from 2 to 14). Likewise, the indicator of controlled motivation is the sum of points assigned to external motivation and introjection, divided by the number of strivings. Originally, the PSA also allows the researcher to calculate the relative autonomous index, one that was excluded from our analyses owing to its failure to meet simplex pattern criteria. ${ }^{2}$

The PSA also allows for calculating indexes expressing the degree to which intrinsic and extrinsic values are realized. These indexes are computed for particular values by adding the points assigned to each value on a 1-7 scale in connection with each striving, and then dividing that value by the number of strivings generated by the participant. The intrinsic values realization index is the sum of points assigned to individual intrinsic values (personal growth, community contribution, and intimacy/friendship) divided by the number of the participant's strivings. Likewise, the extrinsic values realization index is the sum of points assigned to individual extrinsic values (attractive appearance, popularity/recognition, and financial success) divided by the number of the strivings. The lowest possible value for each index is 3 and the highest is 21 .

The four indexes mentioned above (autonomous motives, controlled motives, intrinsic values, and extrinsic values) demonstrated satisfactory reliability. Cronbach's alphas for autonomous motives and controlled motives were .80 and .84 , while the coefficients for intrinsic and extrinsic values were .88 and .85 , respectively.

\footnotetext{
2 To test the simplex pattern, we used the procedure developed by Ryan and Connell (1989), one that is also recommended by Chemolli and Gagné (2014). Regression analysis showed a poor fit of the model to the data, with congruence coefficient of $.79, \mathrm{R}^{2}=.63, \mathrm{~F}(1,4)=6.80, p=0.06$.
} 


\section{Results}

\subsection{Descriptive Statistics}

Descriptive statistics for the variables studied are given in Table 1. T-Student test was performed to compare the means for women and men. Women and men did not differ in respect of both the general level of meaning in life (based on both its dimensions taken together) and its two dimensions taken individually, although we observed differences with regard to some of the values and types of motivation. Women scored higher on the mean sum of intrinsic values (women: $M=13.63$, men: $M=12.44, t=3.62, p<.001$ ). Moreover, higher results were observed for women also with respect to particular intrinsic values: personal growth (women: $M=5.62$, men: $M=5.22, t=3.49, p=.001$ ), intimacy/friendship (women: $M=4.37$, men: $M=3.92, t=3.16, p=.002$ ), and community contribution (women: $M=3.64$, men: $M=3.30, t=2.18, p=.03$ ).

No significant differences were found across the genders in the levels of intrinsic and external motivation, although women again scored higher on both introjected motivation (women: $M=3.82$, men: $M=3.46, t=2.14, p=.03$ ) as well as on identified motivation (women: $M=5.50$, men: $M=5.14, t=2.77, p=.01$ ).

\subsection{Preliminary Analyses}

Before setting out to verify our hypotheses, we conducted a preliminary analysis of the relationships between motives and values in personal strivings. We aimed to answer the following question: to what extent are autonomous and controlled motives associated with realizing extrinsic and intrinsic values? By running this analysis we were also able to compare our findings with those of similar investigations (e.g., Sheldon and Kasser 1995; Sheldon et al. 2004). The analysis was performed by examining the motives-values correlations in two different ways, each covering either the level of the person or that of the striving. At the

Table 1 Descriptive statistics for the whole sample $(N=353)$

\begin{tabular}{|c|c|c|c|c|}
\hline & $M$ & Minimum & Maximum & SD \\
\hline PIL scale & 53.58 & 24.00 & 70.00 & 8.70 \\
\hline Exciting life & 37.18 & 16.00 & 49.00 & 6.25 \\
\hline Purposeful life & 16.41 & 7.00 & 21.00 & 3.08 \\
\hline Intrinsic values-sum & 12.98 & 4.38 & 21.00 & 3.12 \\
\hline Self-acceptance/personal growth & 5.40 & 1.00 & 7.00 & 1.10 \\
\hline Intimacy/friendship & 4.12 & 1.00 & 7.00 & 1.33 \\
\hline Community contribution & 3.45 & 1.00 & 7.00 & 1.49 \\
\hline Extrinsic values-sum & 10.72 & 3.00 & 21.00 & 3.48 \\
\hline Physical appearance & 3.09 & 1.00 & 7.00 & 1.38 \\
\hline Popularity/recognition & 3.75 & 1.00 & 7.00 & 1.50 \\
\hline Financial success & 3.88 & 1.00 & 7.00 & 1.42 \\
\hline Intrinsic motivation & 4.75 & 1.00 & 7.00 & 1.36 \\
\hline Identified motivation & 5.30 & 1.00 & 7.00 & 1.22 \\
\hline Introjected motivation & 3.62 & 1.00 & 7.00 & 1.58 \\
\hline External motivation & 2.25 & 1.00 & 6.63 & 1.18 \\
\hline
\end{tabular}


person-level, analysis was performed for autonomous motivation (intrinsic motivation and identification) and controlled motivation (external motivation and introjection). Rather than test individual types of motivation, we chose to use these two indicators, for it made it easier to compare them with the self-determination factor used by other researchers.

Following Sheldon and Kasser (1995), in the first step we measured the overall vertical coherence measure, which assesses the extent to which strivings are helpful in realizing all the six values under examination. This indicator is the arithmetic mean of all the scores assigned to particular values and the number of strivings generated by the participant. Individuals with a higher vertical coherence indicator also scored higher on autonomous motivation $(r=.41$, $p<.001)$ and controlled motivation $(r=.26, p<.001, z=2.24, p=.03)$. Instead of employing the vertical coherence indicator also in the second step, we used the indicators of realizing intrinsic and extrinsic values (see Sect. 2.2.2), to obtain similar results. The correlation between intrinsic values and autonomous motivation was $.39(p<.001)$, with a positive correlation also found for intrinsic values and controlled motivation $(r=.21, p<.001$, $z=2.65, p=008)$. Likewise, extrinsic values correlated with autonomous motivation $(r=.34, p<.001)$ and controlled motivation $(r=.27, p<.001, z=1.03, p=.35)$, while intrinsic values were also significantly correlated with extrinsic values $(r=.64, p<.001)$.

The findings obtained in the course of these analyses are consistent with those reported by Sheldon and Kasser (1995), showing that realizing different values in strivings is facilitated to a greater extent by autonomous than controlled motivation. They also demonstrated both measures of personality integration - that is, motives and values - to be correlated with each other.

Analysis at the striving-level was performed for 2459 personal strivings, $54 \%$ of which were provided by male participants. The results were consistent with those obtained in the person-level analysis: intrinsic values were correlated more strongly with $\mathrm{z}$ autonomous motivation $(r=.24, p<.001)$ than controlled motivation $(r=.11, p<.001, z=4.67$, $p<001)$. Correspondingly, similar levels were found for the correlations between extrinsic values and autonomous motivation $(r=.18, p<.001)$ and controlled motivation $(r=.14$, $p<.001, z=1.43, p=15$ ) (to test differences between described correlations we used suitable tool by Lee and Preacher 2013a, b) We were unable to replicate Sheldon et al.'s (2004) findings, which showed that pursuing extrinsic values was mainly driven by controlled motivation.

\subsection{Values and Meaning in Life}

\subsubsection{Correlations}

Analyses of correlation and regression (Tables 2, 3, respectively ) were performed to verify hypothesis $\mathrm{H} 1$, which predicted that realizing intrinsic values in personal strivings is positively related to meaning in life.

The correlations obtained fully supported the hypothesis in that all the intrinsic values were weakly — even though statistically significantly-related to general meaning in life and both of its dimensions. These relationships were observed for both female and male participants, although there were gender differences with respect to particular values. ${ }^{3}$ The values of intimacy/friendship and community contribution demonstrated substantially

\footnotetext{
3 To test whether correlation coefficients obtained for women and men were statistically different, we used calculation for the test of the difference between two independent correlation coefficients (Preacher 2002). The same tool was also used for further calculations described below.
} 
Table 2 Correlations between values and meaning in life for the whole sample $(N=353)$, women (F) $(n=159)$, and men (M) $(n=194)$

\begin{tabular}{|c|c|c|c|c|c|c|c|c|c|}
\hline & \multicolumn{3}{|c|}{ PIL scale } & \multicolumn{3}{|c|}{ Exciting life } & \multicolumn{3}{|c|}{ Purposeful life } \\
\hline & All & $\mathrm{F}$ & M & All & $\mathrm{F}$ & M & All & $\mathrm{F}$ & M \\
\hline Intrinsic values-sum & $.30 * *$ & $.33 * *$ & $.27 * *$ & $.29 * *$ & $.29 * *$ & $.28 * *$ & $.26 * *$ & $.34 * *$ & $.19 *$ \\
\hline $\begin{array}{l}\text { Self-acceptance/personal } \\
\text { growth }\end{array}$ & $.22 * *$ & $.22 *$ & $.21 *$ & $.20 * *$ & $.19 *$ & $.21 *$ & $.20 * *$ & $.24 *$ & $.17 *$ \\
\hline Intimacy/friendship & $.28 * *$ & $.32 * *$ & $.24 *$ & $.27 * *$ & $.28 *$ & $.25^{* *}$ & $.24 * *$ & $.33 * *, \mathrm{a}$ & $.16^{*, \mathrm{~b}}$ \\
\hline Community contribution & $.22 * *$ & $.26^{*}$ & $.17 *$ & $.21 * *$ & $.24 *$ & $.19 *$ & $.18^{*}$ & $.26^{*, \mathrm{a}}$ & $.11^{\mathrm{b}}$ \\
\hline Extrinsic values-sum & $.23 * *$ & $.16^{*}$ & $.28 * *$ & $.22 * *$ & .15 & $.27 * *$ & $.20 * *$ & .15 & $.23 *$ \\
\hline Physical appearance & .10 & .07 & .12 & .10 & .05 & .13 & .09 & .09 & .10 \\
\hline Popularity/recognition & $.16^{*}$ & $.05^{\mathrm{a}}$ & $.23^{*, \mathrm{~b}}$ & $.17 *$ & .07 & $.23 *$ & $.12 *$ & $.02^{\mathrm{a}}$ & $.19^{*, \mathrm{~b}}$ \\
\hline Financial success & $.29 * *$ & $.27 *$ & $.31 * *$ & $.27 * *$ & $.24 *$ & $.29 * *$ & $.28 * *$ & $.27 *$ & $.28 *$ \\
\hline
\end{tabular}

$* * p<.000 ; * p<.05 ; \mathrm{a}, \mathrm{b}$ difference $(p<.05)$

Table 3 Results of regression analysis for the dependent variable of general meaning in life and the independent variables of values

\begin{tabular}{|c|c|c|c|c|c|c|}
\hline & Beta & $t(187)$ & $p$ & \multicolumn{3}{|c|}{ Partial correlation } \\
\hline \multicolumn{7}{|l|}{$\operatorname{Men}(n=194)$} \\
\hline \multicolumn{7}{|c|}{ Variables entered $F(5,187)=4.88, \mathrm{p}<.001, R=.34, \mathrm{R}^{2}=.115$, adjusted $\mathrm{R}^{2}=.09$} \\
\hline Self-acceptance/personal growth & .09 & 1.13 & .26 & \multicolumn{3}{|l|}{.08} \\
\hline Intimacy/friendship & .09 & 1.01 & .31 & \multicolumn{3}{|l|}{.07} \\
\hline Community contribution & .01 & .08 & .93 & \multicolumn{3}{|c|}{.006} \\
\hline Popularity/recognition & .01 & .12 & .91 & \multicolumn{3}{|c|}{.009} \\
\hline \multirow[t]{2}{*}{ Financial success } & .23 & 2.57 & .01 & \multicolumn{3}{|l|}{.19} \\
\hline & & & & Beta & $t(192)$ & $p$ \\
\hline \multicolumn{7}{|c|}{ Accepted model $F(1,192)=17.73, \mathrm{p}<.001, R=.31, R^{2}=.085$, Adjusted $R^{2}=.08$} \\
\hline \multirow[t]{2}{*}{ Financial success } & & & & .29 & 4.21 & $<.001$ \\
\hline & Beta & $t(154)$ & $p$ & \multicolumn{3}{|c|}{ Partial correlation } \\
\hline \multicolumn{7}{|l|}{ Women $(n=159)$} \\
\hline \multicolumn{7}{|c|}{ Variables entered $F(4,154)=5.53, p<.000, R=.29, R^{2}=.13$, Adjusted $R^{2}=.10$} \\
\hline Self-acceptance/personal growth & .04 & .47 & .64 & \multicolumn{3}{|l|}{.04} \\
\hline Intimacy/friendship & .21 & 2.05 & .04 & \multicolumn{3}{|l|}{.16} \\
\hline Community contribution & .05 & .51 & .61 & \multicolumn{3}{|l|}{.04} \\
\hline \multirow[t]{2}{*}{ Financial success } & .14 & 1.53 & .13 & \multicolumn{3}{|l|}{.12} \\
\hline & Beta & & & & $p$ & \\
\hline
\end{tabular}

Accepted model $F(1,157)=17.50, p<.001, R=.32, R^{2}=.10$, Adjusted $R^{2}=.095$

Intimacy/friendship

.32

4.18

$<.001$ 
stronger correlations with the purposeful life dimension in the group of women than in men. For men, even though it reached statistical significance, the correlation of intimacy/ friendship with meaning in life was very low, if not marginal.

Interesting to note, female participants demonstrated a significantly stronger relationship between intrinsic values and meaning in life along with both of its dimensions than between extrinsic values. Statistical significance of the differences between the correlation coefficients was determined by using Steiger's test: the difference between the correlation of the scale of general meaning in life and the sum of intrinsic values and the correlation of the scale of general meaning in life and the sum of extrinsic values was $z=2.44$, $p=.007$; the difference between the correlation of exciting life and the sum of intrinsic values and the correlation of exciting life and the sum of extrinsic values was $z=-2.01$, $p=.02$; and the difference between the correlation of purposeful life and the sum of intrinsic values and the correlation of purposeful life and the sum of extrinsic values was $z=2.78, p=.002$. These results show that in women the correlations between meaning in life and intrinsic values were significantly higher than between extrinsic values. No such differences were observed in the group of men.

Apart from supporting the proposed hypothesis, the findings also provided new information on the relationship between values and meaning in life. More specifically, they showed that meaning in life is not only related to intrinsic values but also to extrinsic ones, a relationship that is particularly pronounced in the case of financial success, a value which correlates positively with meaning in life in women as well as in men. Another extrinsic value, popularity/recognition, is differentially related to meaning in life across both groups: whereas in the group of women this relationship failed to reach statistical significance, in the group of men it was statistically significant and substantially higher. The third extrinsic value, physical appearance, demonstrated no correlation with meaning in life.

\subsubsection{Regression}

Enter method regression analysis (Statistical Package for the Social Sciences) was carried out to answer the question of which values realized in personal strivings are the best predictors of meaning life. Multiple regression was performed separately for women and men because correlation analysis showed the difference between correlations in both groups to be statistically significant. In both analyses, only the variables that significantly correlated with general meaning in life were entered into regression (Table 3). Moreover, we also took account of partial correlation analysis when considering the variables that could be significant for creating the model.

In the last step of the analysis, financial success was the only extrinsic value that was a significant predictor of meaning in life in the group of men. In contrast, the intrinsic value of intimacy/friendship was found to be a predictor of meaning in life in the group of women. In both these cases the total percentage of explained variance in general meaning of life was 10 .

\subsection{Types of Motivation and Meaning in Life}

\subsubsection{Correlations}

To verify the hypothesis of a positive relationship between intrinsic motivation and meaning in life (hypothesis $\mathrm{H}_{2 \mathrm{a}}$ ) and a negative relationship between external motivation and meaning in life $\left(\mathrm{H}_{2 \mathrm{~b}}\right)$, correlations between these variables were calculated for the whole sample as well as separately for women and men (Table 4). 
Table 4 Correlations between types of motivation and meaning in life for the whole sample $(N=353)$, women $(\mathrm{F})(n=159)$, and men $(\mathrm{M})(n=194)$

\begin{tabular}{|c|c|c|c|c|c|c|c|c|c|}
\hline & \multicolumn{3}{|c|}{ PIL scale } & \multicolumn{3}{|c|}{ Exciting life } & \multicolumn{3}{|c|}{ Purposeful life } \\
\hline & All & $\mathrm{F}$ & M & All & $\mathrm{F}$ & $\mathrm{M}$ & All & $\mathrm{F}$ & M \\
\hline $\begin{array}{l}\text { Intrinsic } \\
\text { motivation }\end{array}$ & $.24 * *$ & $.26^{*}$ & $.21^{*}$ & $.22 * *$ & $.23 *$ & $.21 *$ & $.22 * *$ & $.28 * *$ & $.17^{*}$ \\
\hline $\begin{array}{l}\text { Identified } \\
\text { motivation }\end{array}$ & $.13^{*}$ & .13 & .12 & .12 & .12 & .12 & $.11 *$ & .11 & .10 \\
\hline $\begin{array}{l}\text { Introjected } \\
\text { motivation }\end{array}$ & .02 & -.12 & .13 & .03 & -.10 & .13 & .01 & -.12 & .11 \\
\hline $\begin{array}{l}\text { External } \\
\text { motivation }\end{array}$ & $-.25^{* *}$ & $-.36^{*, a}$ & $-.15^{*, \mathrm{~b}}$ & $-.24 * *$ & $-.34 * *, \mathrm{a}$ & $-.16^{*, \mathrm{~b}}$ & $-.20 * *$ & $-.32^{*, \mathrm{a}}$ & $-.10^{\mathrm{b}}$ \\
\hline
\end{tabular}

$* * p<.000 ; * p<.05 ; \mathrm{a}, \mathrm{b}$ difference $(p<.05)$

The results confirmed $\mathrm{H}_{2 \mathrm{a}}$-there is a positive relationship between intrinsic motivation and meaning in life, and supported $\mathrm{H}_{2 \mathrm{~b}}$ - as expected, external motivation demonstrated a significant negative relationship with meaning in life and its dimensions.

Hypothesis $\mathrm{H}_{2 b}$ proved relevant to the female participants of the study: in this group, correlations between external motivation and meaning in life, exciting life, and purposeful life were all moderately strong coefficients. Conversely, in the group of men these coefficients were significantly lower and characterized by a weaker strength of relationship.

The two intermediate forms of behavior regulation (identified motivation and introjected motivation) were either non-significant or very low coefficients that defied interpretation.

\subsubsection{Regression}

Simple regression was used to determine the percentage of total variance in general meaning in life explained by particular motives. We used a procedure identical to the one described above and entered to the regression model the types of motivation that had been found to be significantly correlated with general meaning in life in both gender groups.

For women, significant predictors of meaning in life included intrinsic motivation, $\beta=.22, p=.003$, and external motivation, $\beta=-.33, p<.001$. The regression model was a good fit to the data, $F(2156)=16.96, p<.001$, and explained $17 \%$ of variance in meaning in life. For men, a predictor of meaning in life was intrinsic motivation, $\beta=.21$, $p=.003$, which however explained merely $4 \%$ of variance in the variable, $F(1$, 192) $=8.84, p=.003$.

The next aim of the study was to identify the strongest predictors of meaning in life for women and men. This was done using enter method regression (Table 5), which included together all the values under consideration, as well intrinsic and external motivation.

Similarly to earlier analyses, regression demonstrated that financial success, as a value realized in personal strivings, is the best predictor of meaning in life for men. Moreover, also external motivation proved to be a predictor of meaning in life in this group.

In turn, the results for women seemed consistent with the assumptions of SDT in that they showed external motivation and the intrinsic value of intimacy/friendship to be the best predictors of meaning in life in this group, together explaining $20 \%$ of variance. 
Table 5 Results of regression analysis for the dependent variable of general meaning in life and the independent variables of values and types of motivation

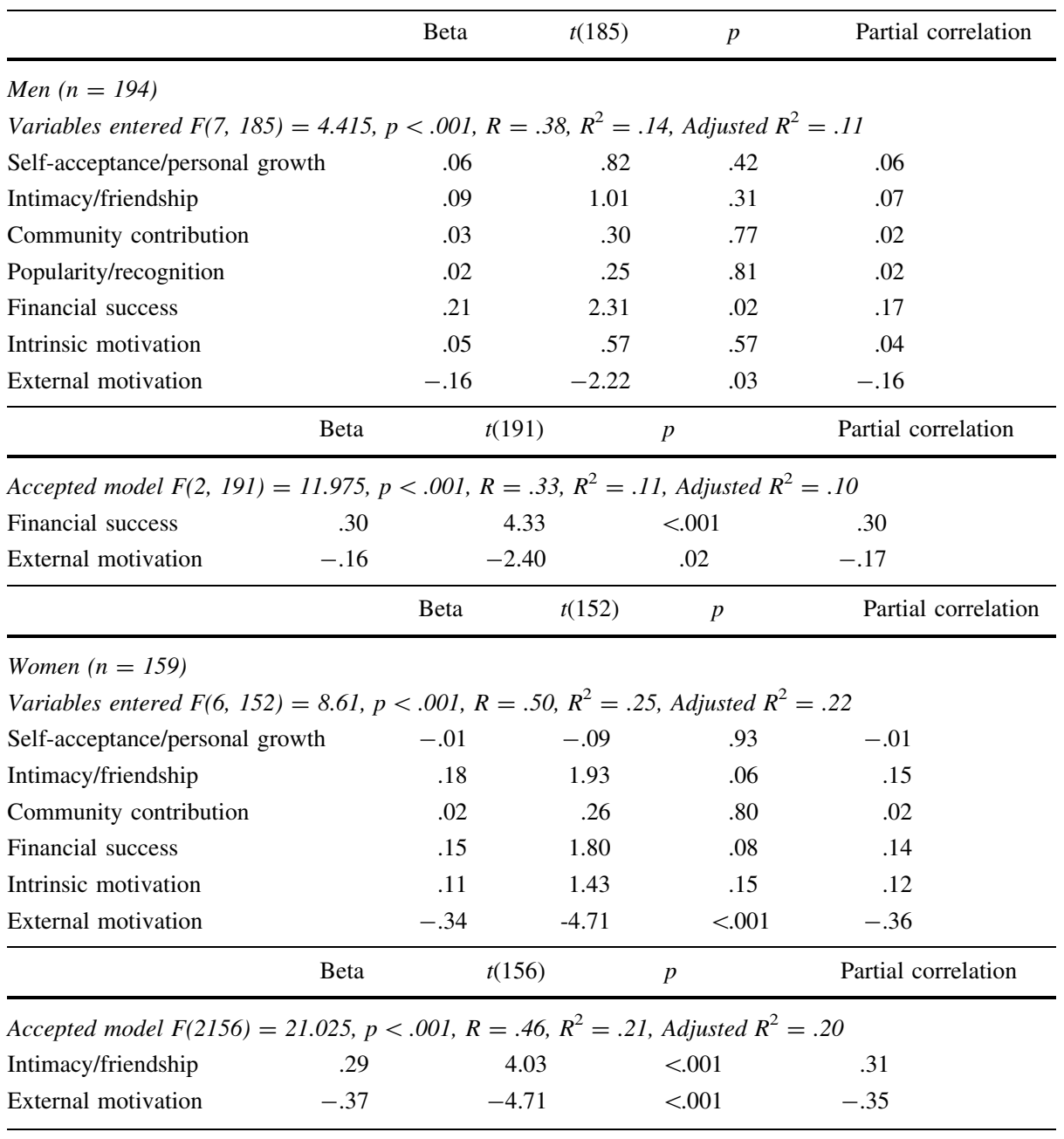

\subsubsection{Low and High Levels of Meaning in Life}

T-Student test was performed to answer the question of whether participants with different levels of meaning life also differed with respect to the types of types, and the levels of intrinsic and extrinsic values realized in everyday strivings. Participants were divided into the low- and high-meaning in life groups based on quartiles (lower and upper quartiles for women $=50$ and 60 PIL points, respectively; lower and upper quartiles for men $=48$ and 60 PIL points, respectively). Thus, meaning in life was included as an independent variable in this analysis. The results are given in Table 6 . For the reason that variances were not homogeneous, the table shows the results of the t-Student test assuming inequality of variance. 


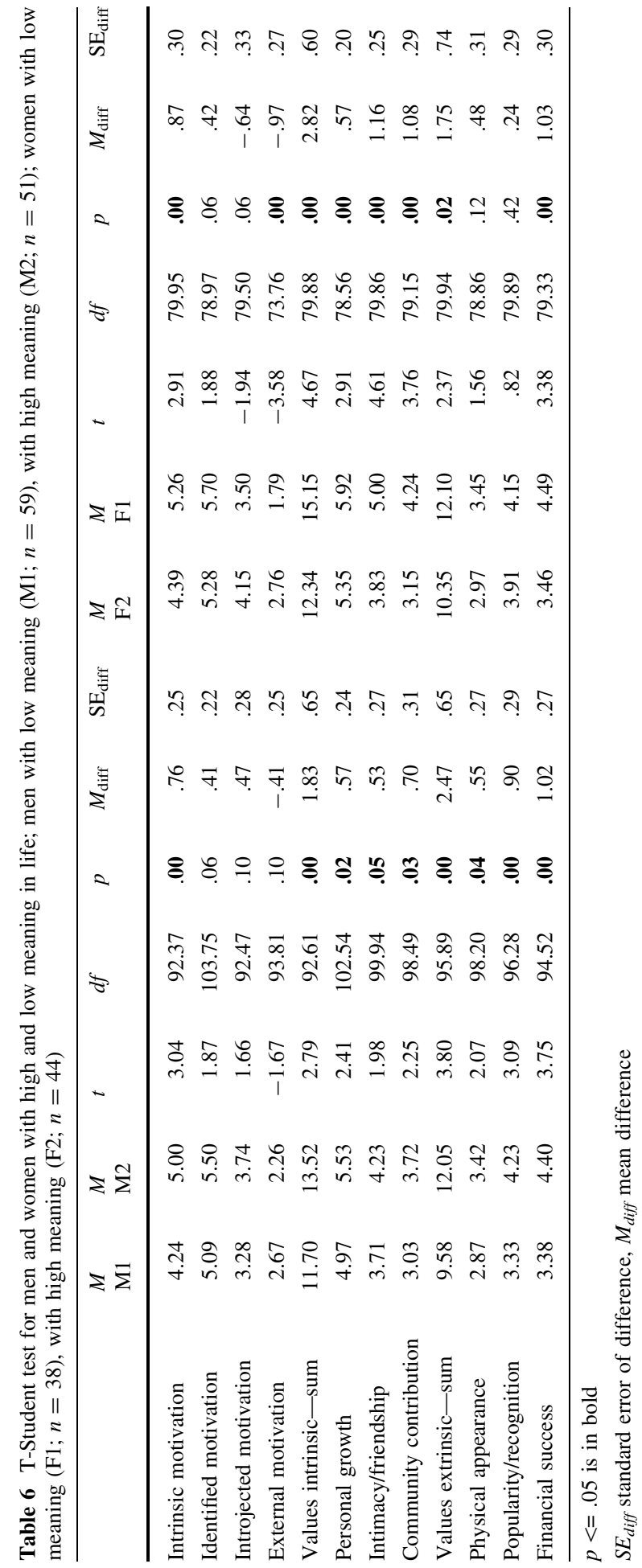


The results showed that low- and high-meaning in life individuals differed significantly in that the latter scored higher on intrinsic motivation. In women, this difference was also present with respect to the level of external motivation: women with high meaning in life also demonstrated significantly lower levels of external motivation.

Moreover, differences were also found between low- and high-meaning in life participants with respect to the values studied: participants in the latter group (both women and men) were also those who identified their personal strivings as realizing intrinsic as well as extrinsic values. In men, this effect was observed with regard to all the extrinsic values and two of the three intrinsic ones, with intimacy/friendship being the only value that failed to reach statistical significance. In the group of women, low- and high-meaning in life participants differed in respect of all the three intrinsic values and financial success. Such findings are consistent with the correlations shown in Table 2 and allow for determining the probable direction of these relationships.

\section{Discussion}

This study examined the relationships between meaning in life and values realized by individuals, and between meaning in life and autonomous and controlled motives. The results provided information on the strongest predictors of meaning life, which turned out to differ across the sexes: the strongest predictor for men is the extrinsic value of financial success, whereas for women-the intrinsic value of intimacy/friendship. Interesting to note, both of these predictors explained only approximately $10 \%$ of variance in meaning in life. In other words, one's level of meaning in life is largely influenced also by a number of other factors (one of those most significant is external motivation).

The findings obtained for women are consistent with a host of theoretical models that emphasize the importance of relations with others for an individual's development, happiness, and sense of purpose (including Bowlby 1997; Armsden and Greenberg 1987). Relatedness is one of the three basic psychological needs distinguished by Deci and Ryan (2002) that play an instrumental part in the development of autonomy, while Frankl (1959/ 2006) considers intimacy, friendship and love to be the values on which individuals build their permanent sense of meaning and purpose in life.

The ability to establish and maintain close relationships with others is regarded by psychologists as one of the most important abilities and an indicator of adequate social adaptation and proper human development (Erikson 1982; Bowlby 1997; Noom et al. 1999). Along the same lines, alienation and lack of close relationships are the problems often experienced along with mental and personality disorders. A paucity of satisfying relationships and a sense of exclusion or alienation may also give rise to a range of other social problems, including susceptibility to addiction and joining groups that pose a threat to the individual, such as sects (Armsden and Greenberg 1987; Lee and Bell 2003). In this light, intimacy/friendship is the value whose role as a predictor of meaning in life appears to be most justified. However, the question remains of why this value has no predicting power for men. A breadth of research shows that women, as opposed to men, are more altruistic toward other people (Rushton et al. 1986; Fabes and Eisenberg 1998) and regard the issues pertaining to interpersonal relations as more important, both of which features are expressed in women's greater involvement in establishing and maintaining social relations (Moen 1996). Hence, these results may perhaps provide yet further confirmation of the differences existing in this respect between the two sexes. 
An important finding that indicates the importance attached to the extrinsic value of financial success by men appears to be inconsistent with the hypotheses proposed here, with the results of earlier research (e.g. Kasser and Ryan 1993, 1996), and with the assumptions of SDT (Deci and Ryan 2002). There are at least two ways in which to interpret this result. One of them is to scrutinize the cultural and socioeconomic situation of the examined population.

The standard of living in Poland is substantially lower than that enjoyed by people in the USA or Germany (GDP per capita in the USA and Germany is more than twice the level in Poland; e.g. based on the data by World Bank 2014; OECD 2014), Poland also being one of the poorest members of the European Union (World Bank 2014; OECD 2014; Statistical Office of the European Communities 2014). Similarly to Sheldon and Kasser's 1998 study, financial success was defined here as "having a job that pays very well and having a lot of nice possessions".

In Poland, young adults with only average salaries effectively lack the wherewithal to take out a more considerable bank loan or mortgage, also being often unable to pay for their education and cover the costs of improving their professional qualifications. Therefore, it seems that only by achieving financial success, understood as finding a well-paid job and earning an above-average salary, are young Poles able to attain a sense of security and financial independence. Why, then, did financial success prove to be a significant predictor of meaning in life only for men? Again, this may at least in part be explained when placed in a broader cultural context.

Despite high employment rates for women (Ministry of Labour and Social Policy 2014) and a variety of successful gender equality policies, in Poland men consistently earn more than women (Supreme Audit Office 2013), making them also responsible for supporting their families to a much greater extent. It is perhaps in the light of the current social and economic situation that young Polish men perceive financial success as means to fulfilling their dreams, for instance, about no longer having to depend financially on their parents, becoming fully independent and self-reliant, and being able to start a family. These goals are characteristic of this population and very much in accordance with relevant developmental tasks (e.g. Havighurst 1972; Erikson 1982). Moreover, it is also worthwhile to refer to the theory of evolution. The findings of a wealth of intercultural research performed globally are consistent with respect to the fact that, in choosing their partners, women value material resources, promising financial prospects, and high social position of the candidates. Hence, meeting these criteria is seen as substantially improving one's chances of finding the appropriate female partner to start a family with (Buss 1999).

Such perceived "financial success" can be understood as more than merely an immature way of creating the sense of one's worth by satisfying social expectations and accumulating possessions and money. Therefore, rather than viewing financial success as an expression of materialism, an interpretation may be put forward which focuses on the relationship between meaning in life and financial success defined as a condition for attaining independence, financial security, and the capacity to establish intimate relations with others. However, the results obtained fail to provide a definite answer to the question of whether the participants of our study associated "financial success" with strivings that were a manifestation of materialism, or with those related to reaching independence and financial security.

Such an interpretation of our findings can also be supported by referring to earlier research. Kasser's (2013) already-mentioned meta-analysis demonstrates that the negative effect of focusing on material success is less pronounced in the poorer countries than in the highly-developed ones. The intuitive reasoning that extrinsic strivings are differentially understood in wealthy, as opposed to poor, countries is also given support in a study by 
Grouzet et al. (2005). Examining the structures of values pursued across different cultures, the researchers observe that whereas people living in the wealthier, highly-developed countries tend to associate financial success with hedonistic values, people inhabiting the poorer countries are more likely to associate it with values related to security and health.

Similar conclusions can be found in a study by Inglehart (1995). It presents Poland, with its predominantly materialistic orientation, in opposition to the developed countries of the West, with their orientation to post-modern and post-materialistic values, such as tolerance, trust, ecology, and life satisfaction. Despite the objective changes that have taken place there, Poland is a country that is "working its way up". The Polish middle-class is striving to achieve financial success and thus advance their social standing, a goal undoubtedly pursued by the students making up our sample (Ziółkowski 2000).

Moreover, additional support for this interpretation can also be sought in the relatively few studies based on the data obtained for Eastern European populations, and a limited number of other studies, such as the research conducted by Srivastava et al. (2001), where the relationship between materialism and well-being is given further clarification. According to the authors of that study, what is of primary importance is the de facto reason why the individual wants to achieve financial success. Their findings reported that the desire to impress others, striving for power, and compensating for one's low self-esteemthat is, reasons that could be classified as controlled ones under SDT-did in fact correlate with lower levels of well-being.

Still another perspective to be taken into consideration in interpreting our findings is the one related to the debatable validity of the PIL. One can assume that financial success is not so much a means to enjoying a purposeful life as to achieving economic security. In other words, realizing financial success could be associated with lower distress and a happier frame of mind, an interpretation that would be largely congruent with the theory that forms the bedrock of this study. Against accepting this explanation (as the more accurate one) stands the fact that rather than using the PIL in its complete form-which is the target of a majority of the reservations mentioned above-we employed only a selection of ten items making up the original tool. The methodological and statistical parameters of these items, as well as their content, may be indicative of relatively high internal validity (Morgan and Farsides 2009; Schulenberg and Melton 2010). Furthermore, compared with other tools for assessing meaning in life (e.g., The Meaning in Life Questionnaire), the PIL is characterized by superior psychometric indicators in the Polish conditions (Kossakowska et al. 2013).

Regression analysis revealed the strongest predictors of meaning in life, which explained the greatest percentage of variance. It should be borne in mind, however, that we also observed a high correlation between extrinsic and intrinsic values, as financial success and intimacy/friendship correlated with other values as well. In the group of men, financial success produced the strongest correlation with another extrinsic value, namely popularity/ recognition $(r=.61)$. A correspondingly high relationship in the group of women was found between the values of intimacy/friendship and community contribution $(r=.60)$.

Consequently, even though we were able to single out the strongest predictors from the pool of the values studied, account must be taken of the interrelations that bind them.

Another interesting finding was provided by regression analysis, which included values as well as motivations. It showed that external motivation is important for predicting the level of meaning in life among both female and male participants. The lower the level of external motivation in strivings, the higher meaning in life. Acting under pressure and realizing strivings for the sake of external judgment and rewards, a characteristic feature of controlled motivation, is exceptionally unfavorable for shaping meaning in life. This 
finding may be interpreted to confirm the theses under self-determination theory, which assume a negative impact of external motivation on human well-being.

Still another issue worth discussing is related to the differences observed between individuals with low- and high-meaning in life, which is yet another area with differential results across the sexes. The question that motivated our analysis was: How do people differing in meaning in life levels perceive and evaluate their everyday strivings (everyday activities) in relation to the values they realize and their underlying motivations? The results obtained are hardly surprising, with the main conclusion being that, irrespective of their gender, participants with a high sense of meaning in life are more likely to associate their strivings with motivation driven by autonomous regulation, as compared with controlled motivation. In other words, such individuals are to a lesser extent motivated by punishment, praise, pressure, and expectations of others than by their curiosity, pleasure, and the importance of their goals and strivings seen through the prism of their own needs, expectations, internalized values, and similar types of motivation. What is more, in their strivings people with higher meaning in life also reveal a higher degree of subjectivity, which may be conducive to a greater activity in pursuing goals and increased satisfaction derived from their achievement. These results also show that people with high meaning in life endow their everyday strivings with greater meaning by associating them more closely with the pursuit of particular values, which makes their activity appear to be more thought out and focused. Put differently, this group of participants exhibited an openness to meaning-making values, irrespective of their character, a feature that also allowed them to perceive their strivings as those that produce meaning (Straś-Romanowska 2005). Such a perception of one's own strivings may serve as a secondary reinforcer for meaning in life.

The findings reported in this study, in particular the results observed for men, may be related to the effects observed in earlier research by Brdar et al. (2009). Analyzing Croatian students' intrinsic and extrinsic aspirations and their relationships with well-being, the researchers observed the highest levels of well-being in people scoring high on both intrinsic as well as extrinsic strivings. Similar observations were made on a population of Russians (Ryan et al. 1999), in which case intrinsic and extrinsic aspirations were positively correlated with one of the dimensions of well-being, namely life satisfaction.

In a sense, the male participants of our study behaved similarly to their Croatian and Russian counterparts. Analyzing their strivings, men with high levels of meaning in life perceived them as realizing all the extrinsic and part of the intrinsic values. Correspondingly, those with low levels of meaning in life also reported decidedly weaker ties between values and the strivings they realized. It is probable that low-meaning in life individuals assume a passive, if not reactive, attitude toward the world around, and rarely ponder on long-term results of their everyday strivings. This situation may have its origin in the early influence of family and social environments (Grolnick et al. 1997; Beyers et al. 2007; Grolnick et al. 2007), which in the case of those study participants failed to support the development of autonomy and self-awareness, also offering insufficient opportunity to make independent choices and plan their future actions.

The final question worth discussing here is the importance of extrinsic values for meaning in life. It will be recalled that men with high levels of meaning in life show a predominance of extrinsic values, while intrinsic values were found to be predominant for their female counterparts. It is perhaps the case that realizing extrinsic values does not bring about a negative effect of lowering well-being, and thus also decreasing meaning in life, provided that individuals also realize intrinsic values in their strivings.

The authors of SDT often emphasize they are far from denouncing the desire for seeking extrinsic rewards as such, as these rewards only threaten personal development and 
personality integration when they become the object of excessive focus (Deci and Ryan 1985). In light of the findings reported in this study, it is safe to argue that people's developing of their sense of meaning in life is affected negatively not only by their excessive concentration on pursuing external rewards, but also by inadequate awareness of their goals, motivations, and the values they could realize through their actions.

\section{Limitations}

This study has certain limitations that we intend to circumvent in future research. To determine conclusively that realizing intrinsic and extrinsic values is equally related to meaning in life, the procedure of the study ought to be expanded to include value hierarchization or a process of identifying key strivings. It is difficult to state whether the participants in the current study perceived financial success as the central and most important value, a fact that considerably limits our capacity to interpret these results and compare them with the data collected by others. Furthermore, we plan to perform a qualitative analysis of the data obtained, which will allow for a more precise determination of which strivings young Poles fulfill to realize particular values.

\section{Conclusions}

The present study has demonstrated that realizing values by young adults through everyday strivings is significantly correlated with their sense of meaning in life. The strongest predictors of the level of meaning in life include the intrinsic value of intimacy/friendship and the extrinsic value of financial success, as well as external motivation.

The findings, which showed that interesting differences exist between the genders, also require further exploration.

Moreover, the results reported here on the relationships between values and meaning in life differ from those obtained in the wealthier Western countries, which could perhaps be explained in socioeconomic, political, and cultural terms. Poland is now a country of an intensive economic development, one characterized by life satisfaction that has been continuously on the rise for the past 25 years or so. This gives basis to expect that young people's attitude to values and their preference for either intrinsic or extrinsic values will also change as the country develops and grows wealthy, which in itself creates an opportunity for promising future investigations.

Open Access This article is distributed under the terms of the Creative Commons Attribution 4.0 International License (http://creativecommons.org/licenses/by/4.0/), which permits unrestricted use, distribution, and reproduction in any medium, provided you give appropriate credit to the original author(s) and the source, provide a link to the Creative Commons license, and indicate if changes were made.

\section{References}

Allport, G. W., \& Ross, J. M. (1967). Personal religious orientation and prejudice. Journal of Personality and Social Psychology, 6, 432-443. doi:10.1037/h0021212.

Armsden, G. C., \& Greenberg, M. T. (1987). The inventory of parent and peer attachment: Individual differences and their relationship to psychological well-being in adolescence. Journal of Youth and Adolescence, 16(5), 427-454. doi:10.1007/BF02202939. 
Bailey, T. H., \& Phillips, L. J. (2015). The influence of motivation and adaptation on students' subjective well-being, meaning in life and academic performance. Higher Education Research \& Development,. doi:10.1080/07294360.2015.1087474.

Bandura, A. (1996). Self-efficacy: The exercise of control. New York, NY: Freeman.

Beyers, W., Ryan, R. M., Soenens, B., Vanstennkiste, M., Lens, W., Luykx, K., \& Goosens, L. (2007). Conceptualizing parental autonomy support: Adolescent perceptions of promotion of independence versus promotion of volitional functioning. Developmental Psychology, 43(3), 633-646. doi:10.1037/ 0012-1649.43.3.633.

Bowlby, J. (1997). Attachment and loss (Vol. 1). Attachment, London: Pmilico.

Brdar, I., Rijavec, M., \& Miljković, D. (2009). Life goals and well-being: Are extrinsic aspirations always detrimental to well-being? Psychological Topics, 18(2), 317-334.

Brunelli, C., Bianchi, E., Murru, L., Monformoso, P., Bosisio, M., Gangeri, L., et al. (2012). Italian validation of the purpose in life (PIL) test and the seeking of noetic goals (SONG) test in a population of cancer patients. Supportive Care in Cancer, 20(11), 2775-2783. doi:10.1007/s00520-012-1399-6.

Buss D. M. (1999). Evolutionary psychology. The new science of the mind. First Edition by David M. Buss. Allyn \& Bacon, a Pearson Education Company.

Cantor, N., Norem, J., Langston, Ch., Zirkel, S., Fleeson, W., \& Cook-Flannagan, C. (1991). Life tasks and daily life experience. Journal of Personality, 59(3), 425-451. doi:10.1111/j.1467-6494.1991.tb00255.

Cepuch, G., Debska, G., Pawlik, L., \& Mazurek, H. (2014). Patient's perception of the meaning of life in cystic fibrosis-Its evaluation with respect to the stage of the disease and treatment. Advances in Hygiene and Experimental Medicine, 66, 714-721.

Chemolli, E., \& Gagné, M. (2014). Evidence against the continuum structure underlying motivation measures derived from self-determination theory. Psychological Assessment, 26(2), 575-585. doi:10.1037/ a0036212.

Cohen, K., \& Cairns, D. (2012). Is searching for meaning in life associated with reduced subjective wellbeing? Confirmation and Possible Moderators, Journal of Happiness Studies, 13(2), 313-331. doi:10. 1007/s10902-011-9265-7.

Crumbaugh, J. C. (1968). Cross-validation of purpose-in-life test based on Frankl's concepts. Journal of Individual Psychology, XX, 74-81.

Crumbaugh, J. C., \& Maholick, L. T. (1964). An experimental study in existentialism: The psychometric approach to Frankl's concept of noogenic neurosis. Journal of Clinical Psychology, 20(2), 200-207. doi:10.1002/1097-4679(196404)20:2<200::AID-JCLP2270200203>3.0.CO;2-U.

de Muijnck, W. (2013). The meaning of lives and the meaning of things. Journal of Happiness Study, 14, 1291-1307. doi:10.1007/s10902-012-9382.

Deci, E. L., \& Ryan, R. M. (1985). Intrinsic motivation and self-determination in human behavior. New York: Plenum Press.

Deci, E. L., \& Ryan, R. M. (2002). Handbook of self-determination research. Rochester, NY: University of Rochester Press.

Deci, E. L., Ryan, R. M., Gagné, M., Leone, D. R., Usunov, J., \& Kornazheva, B. P. (2001). Need satisfaction, motivation, and well-being in the work organizations of a former Eastern Bloc country. Personality and Social Psychology Bulletin, 27, 930-942. doi:10.1177/0146167201278002.

Dyck, M. J. (1987). Assessing logotherapeutic constructs: Conceptual and psychometric status of the purpose in life and seeking of noetic goals tests. Clinical Psychology Review, 7, 439-447.

Emmons, R. A. (1986). Personal strivings: An approach to personality and subjective well-being. Journal of Personality and Social Psychology, 51(5), 1058-1068. doi:10.1037/0022-3514.51.5.1058.

Emmons, R. A. (2003a). The psychology of ultimate concerns. New York, London: The Guilford Press.

Emmons, R. A. (2003b). Personal goals, life meaning, and virtue: Wellsprings of a positive life. In C. L. M. Keyes (Ed.), Flourishing: The positive person and the good life (pp. 105-128). Washington, DC: American Psychological Association.

Erikson, E. H. (1982). The life cycle completed. New York, NY: Norton.

Fabes, R. A., \& Eisenberg, N. (1998). Prosocial development. In W. Damon (Ed.), Handbook of child psychology (5th ed.). New York, NY: J. Wiley.

Frankl, V. E. (1978). Psychotherapy and existentialism: Selected papers on logotherapy. New York: Penguin Books.

Frankl, V. E. (2006). Man's search for meaning. An introduction to logotherapy. Boston, MT: Beacon Press.

Grolnick, W. S., Deci, E. L., \& Ryan, R. M. (1997). Internalization within family: The self-determination theory perspective, W: J. E. Gruses I L. Kuczynski (red.), Parenting and children's internalization of values: A handbook of contemporary theory (pp. 135-161). New York: NY: Wiley. 
Grolnick, W. S., Farkas, M. S., Sohmer, R., Michaels, S., \& Valsiner, J. (2007). Facilitating motivation in young adolescents: Effects of an after-school program. Journal of Applied Developmental Psychology, 28, 332-344. doi:10.1016/j.appdev.2007.04.004.

Grouzet, F. M., Sheldon, K. M., Kasser, T., Ahuvia, A., Dols, J. M. F., Kim, Y., et al. (2005). The structure of Goal Contents Across 15 Cultures. Journal of Personality and Social Psychology, 89, 800-816. doi:10.1037/0022-3514.89.5.800.

Havighurst, R. J. (1972). Developmental tasks and education. Michigan, MI: D. McKay Co.

Huta, V. (2012). Linking peoples' pursuit of eudaimonia and hedonia with characteristics of their parents: Parenting styles, verbally endorsed values, and role modeling. Journal of Happiness Studies, 13(1), 47-61. doi:10.1007/s10902-011-9249-7.

Inglehart, R. (1995). Changing values, economic development and political change. International Social Science Journal, 145, 379-404.

Kasser, T. (2013, June), Materialism and well-being: A meta-analysis. 5th International conference on selfdetermination theory. Lecture conducted from University of Rochester, Rochester, NY, USA.

Kasser, T., \& Ahuvia, A. (2002). Materialistic values and well-being in business students. European Journal of Social Psychology, 32, 137-146. doi:10.1002/ejsp.85.

Kasser, T., \& Ryan, R. M. (1993). A dark side of the American dream: Correlates of financial success as a central life aspiration. Journal of Personality and Social Psychology, 65, 410-422. doi:10.1037/00223514.65.2.410.

Kasser, T., \& Ryan, R. M. (1996). Further examining the American dream: Differential correlates of intrinsic and extrinsic goals. Personality and Social Psychology Bulletin, 22, 280-287. doi:10.1177/ 0146167296223006.

King, L. A., Hicks, J. A., Krull, J., \& Del Gaiso, A. K. (2006). Positive affect and the experience of meaning in life. Journal of Personality and Social Psychology, 90, 179-196. doi:10.1037/0022-3514.90.1.179.

Kokonyei, G., Reinhardt, M., Pajkossy, P., Kiss, B., \& Demetrovics, Z. (2008). Characteristics of personal strivings and their relationship with life satisfaction. Cognition, Brain, Behavior An Interdisciplinary Journal, 12(4), 409-443.

Kossakowska, M., Kwiatek, P., \& Stefaniak, T. (2013). Sens w życiu. Polska wersja kwestionariusza MLQ (Meaning in Life Questionnaire), (Meaning in life. The Polish version of Meaning in Life Questionnaire MLQ (PL), Psychologia Jakości Życia (Psychology of Quality of Life), 12(2), 111-131. doi:10. $5604 / 16441796.1090786$

Lee, J., \& Bell, N. (2003). Individual differences in attachment-autonomy configurations: Linkages with substance use and youth competencies. Journal of Adolescence, 26, 347-361. doi:10.1016/ S01401971(03)00018-6.

Lee, I. A., \& Preacher, K. J. (2013, September). Calculation for the test of the difference between two dependent correlations with one variable in common [Computer software]. http://quantpsy.org

Lee, I. A., \& Preacher, K. J. (2013, October). Calculation for the test of the difference between two dependent correlations with no variable in common [Computer software]. http://quantpsy.org

Little, B. R. (1983). Personal projects: A rationale and method for investigation. Environment and Behavior, 15(3), 273-309. doi:10.1177/0013916583153002.

Martos, T., \& Kopp, M. S. (2012). Life goals and well-being: Does financial status matter? Evidence from a Representative Hungarian Sample, Social Indicators Research, 105, 561-568. doi:10.1007/s11205011-9788-7.

Maslow, A. H. (1962). Toward a psychology of being. Princeton, NY: Van Nostrand.

Ministry of Labour and Social Policy-Department of Labour Market, Analyses and Statistics Section. (2014). Men's and women's situation on labour market in 2013. Retrieved September 1, 2014. http:// www.mpips.gov.pl/download/gfx/mpips/pl/defaultopisy/7114/7/1/Sytuacja\%20kobiet\%20i\% 20mezczyzn\%20na\%20rynku\%20pracy\%20w\%202013\%20r._2.pdf

McGregor, I., \& Little, B. R. (1998). Personal projects, happiness, and meaning: On doing well and being yourself. Journal of Personality and Social Psychology, 74, 494-512. doi:10.1037/0022-3514.74.2. 494.

Moen, P. (1996). Gender, age, and the life course. In: R. H. Binstock \& L. K. Gorge (Eds.), Handbook of aging and the social sciences. San Diego, CA: Academic Press.

Morgan, J., \& Farsides, T. (2009). Psychometric evaluation of the meaningful life measure. Journal of Happiness Studies, 10, 351-366. doi:10.1007/s10902-008-9093-6.

Noom, M. J., Dekovic, M., \& Meeus, W. H. J. (1999). Autonomy, attachment and psychosocial adjustment during adolescence: A double-edged sword? Journal of Adolescence, 22, 771-778. doi:10.1006/jado. 1999.0269. 
Nygern, B., Ale'x, L., Jonse'n, E., Gustafson, Y., Norberg, A., \& Lundman, B. (2005). Resilience, sense of coherence, purpose in life and self-transcendence in relation to perceived physical and mental health among the oldest old. Aging \& Mental Health, 9(4), 354-362.

OECD. (2014). National accounts at a glance 2014. Paris: OECD Publishing. doi: 10.1787/na_glance-2014en

Patrick, H., Knee, C. R., Canevello, A., \& Lonsbary, C. (2007). The role of need fulfillment in relationship functioning and well-being: A self-determination theory perspective. Journal of Personality and Social Psychology, 92, 434-457. doi:10.1037/0022-3514.92.3.434.

Popielski, K. (1987). Cztowiek-Pytanie otwarte (A Man-An open question. Logotheory and logotherapy studies). Lublin: RW KUL.

Preacher, K. J. (2002, May). Calculation for the test of the difference between two independent correlation coefficients [Computer software]. http://quantpsy.org

Reis, H. T., Sheldon, K. M., Gable, S. L., Roscoe, J., \& Ryan, R. M. (2000). Daily well-being: The role of autonomy, competence, and relatedness. Personality and Social Psychology Bulletin, 26(4), 419-435. doi: $10.1177 / 0146167200266002$.

Reker, G. T. (2000). Theoretical perspective, dimensions, and measurement of existential meaning. In G. T. Reker \& K. Chamberlain (Eds.), Exploring existential meaning: Optimizing human development across the life span (pp. 39-55). Thousand Oaks, CA: Sage Publications.

Rushton, J. P., Fulker, D. W., Neale, M. C., Nias, D. K. B., \& Eysenck, H. J. (1986). Altruism and aggression: The heritability of individual differences. Journal of Personality and Social Psychology, 50, 1192-1198. doi:10.1037/0022-3514.50.6.1192.

Ryan, R. M., Chirkov, V., Little, T., Sheldon, K. M., Timoshina, E., \& Deci, E. (1999). The American dream in Russia: Extrinsic aspirations in two cultures. Personality and Social Psychology Bulletin, 25, 1509-1524. doi:10.1177/01461672992510007.

Ryan, R. M., \& Connell, J. P. (1989). Perceived locus of causality and internalization: Examining reasons for acting in two domains. Journal of Personality and Social Psychology, 57(5), 749-761. doi:10.1037/ 0022-3514.57.5.749.

Ryan, R. M., \& Deci, E. L. (2000). Self-determination theory and the facilitation of intrinsic motivation, social development, and well-being. American Psychologist, 55, 68-78. doi:10.1037/0003-066X.55.1. 68.

Ryff, C. D., \& Singer, B. H. (1998a). The role of purpose in life and personal growth in positive human health. In P. T. P. Wong \& P. S. Fry (Eds.), The human quest for meaning: A handbook of psychological research and clinical applications (pp. 213-235). Mahwah, NJ: Erlbaum.

Ryff, C. D., \& Singer, B. H. (1998b). The contours of positive human health. Psychological Inquiry, 9, 1-28.

Ryff, C. D., \& Singer, B. H. (2006). Best news yet on the six-factor model of well-being. Social Science Research, 35, 1103-1119.

Schmuck, P., \& Kasser, T. (2000). Intrinsic and extrinsic goals: Their structure and relationship to wellbeing in German and US college students. Social Indicators Research, 50, 225-241. doi:10.1023/A: 1007084005278.

Schulenberg, S. E., \& Melton, A. M. A. (2010). A confirmatory factor-analytic evaluation of the purpose in life test: Preliminary psychometric support for a replicable two-factor model. Journal of Happiness Study, 11, 95-111. doi:10.1007/s10902-008-9124-3.

Schulenberg, S. E., Schnetzer, L., \& Buchanan, E. M. (2011). The purpose in life test-short form: Development and psychometric support. Journal of Happiness Study, 12(5), 861-876. doi:10.1007/s10902010-9231-9.

Seligman, M. E. P. (2011). Flourish: A visionary new understanding of happiness and well-being. New York: Free Press.

Shek, D. T. L. (1988). Reliability and factorial structure of the Chinese version of the purpose in life questionnaire. Journal of Clinical Psychology, 44, 384-392. doi:10.1002/1097-4679(198805)44: 3<384::AID-JCLP2270440312>3.0.CO;2-1.

Sheldon, M. K. (1995). Creativity and self-determinaton in personality. Creativity Research Journal, 8(1), 25-36. doi:10.1207/s15326934crj0801.

Sheldon, K. M., \& Kasser, T. (1995). Coherence and congruence: Two aspects of personality integration. Journal of Personality and Social Psychology, 68, 531-543. doi:10.1037/0022-3514.68.3.531.

Sheldon, K. M., \& Kasser, T. (1998). Pursuing personal goals: Skills enable progress but not all progress is beneficial. Personality and Social Psychology Bulletin, 24, 1319-1331. doi:10.1177/ 01461672982412006.

Sheldon, K. M., \& Kasser, T. (2000). Getting older, getting better? Personal Strivings and Personality Maturity Across the Life Span, Developmental Psychology, 37(4), 491-501. doi:10.1037/0012-1649. 37.4.491. 
Sheldon, K. M., Reis, R., \& Reis, H. T. (1996). What makes for a good day? Competence and Autonomy in the Day and in the Person, Personality and Social Psychology Bulletin, 22(12), 1270-1279. doi:10. $1177 / 01461672962212007$.

Sheldon, K. M., Ryan, R. M., Deci, E. L., \& Kasser, T. (2004). The independent effects of goal contents and motives on well-being: It's both what you pursue and why you pursue it. Personality and Social Psychology Bulletin, 30, 475-486. doi:10.1177/0146167203261883.

Srivastava, A., Locke, E. A., \& Bartol, K. M. (2001). Money and subjective well-being: It's not the money, it's the motives. Journal of Personality and Social Psychology, 80(6), 959-971. doi:10.1037/00223514.80.6.959.

Statistical Office of the European Communities. (2014). EUROSTAT: Living standard statistics. Retrieved September 9, 2014. http://epp.eurostat.ec.europa.eu/statistics_explained/index.php/

Steger, M. F., Frazier, P., Oishi, S., \& Kaler, M. (2006). The meaning in life questionnaire: Assessing the presence of and search for meaning in life. Journal of Counseling Psychology, 53, 80-93.

Steger, M. F., Kawabata, Y., Shimai, S., \& Otake, K. (2008). The meaningful life in Japan and the United States: Levels and correlates of meaning in life. Journal of Research in Personality, 42, 660-678.

Straś-Romanowska, M. (2005). Jakość życia w świetle założeń psychologii zorientowanej na osobę (The quality of life in the view of person-oriented psychological approach). Kolokwia Psychologiczne (Psychological Colloquia)13, 265-274.

Supreme Audit Office. (2013). Zapewnienie prawa do jednakowego wynagradzania kobiet $i$ mézczyzn $w$ sektorze publicznym (Law guarantees for equal payment for women and men in public sector). Retrieved September 1, 2014. http://www.nik.gov.pl/plik/id,5806,vp,7510.pdf

World Bank. (2014). GDP per capita (current US\$) 2009-2013. Retrieved September 11, 2014. http://data. worldbank.org/indicator/NY.GDP.PCAP.CD

Waisberg, J. L., \& Starr, M. W. (1999). Psychometric properties of the purpose in life test with a sample of substance abusers. International Forum for Logotherapy, 22, 22-26.

Waterman, A. S. (1993). Two conceptions of happiness: Contrasts of personal expressiveness (eudaimonia) and hedonic enjoyment. Journal of Personality and Social Psychology, 64, 678-691. doi:10.1037/ 00223514.64.4.678.

Weinstein, N., Ryan, R. M., \& Deci, E. L. (2012). Motivation, meaning and wellness: A self-determination perspective on the creation and internalization of personal meanings and life goals. In P. T. P. Wang (Ed.), The human quest for meaning: Theories, research, and applications (pp. 81-106). New York: Routledge Publishers.

Wu, A. M. S., Lei, L. L. M., \& Ku, L. (2013). Psychological needs, purpose in life, and problem video game playing among Chinese young adults. International Journal of Psychology, 48(4), 583-590. doi:10. 1080/00207594.2012.658057.

Yalom, I. D. (1980). Existential psychotherapy. New York: Basic Books.

Ziółkowski, M. (2000). Przemiany interesów i wartości społeczeństwa polskiego (Transformation of interests and values of the Polish society). Poznań: Wydawnictwo Fundacji Humaniora.

Życińska, J., \& Januszek, M. (2011). Test Sensu Życia (Purpose in Life Test, PIL) J.C. Crumbaugha i L.T. Maholicka: analiza psychometryczna (Purpose in life test (PIL) by J.C. Crumbaugh and L.T. Maholick: a psychometric analysis). Czasopismo Psychologiczne (Psychological Journal), 17(1), 133-142. 